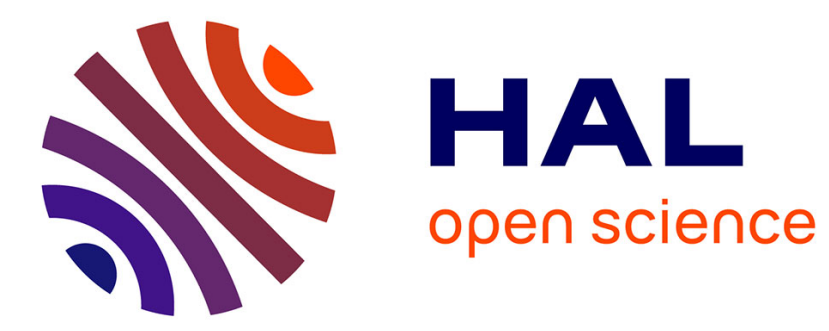

\title{
Subjective posture in tridimensional space
}

I. Israël, I. Giannopulu

\section{To cite this version:}

I. Israël, I. Giannopulu. Subjective posture in tridimensional space. Journal of Vestibular Research, 2012, 22 (4), pp.173-180. 10.3233/VES-2012-0450 . hal-02398141

\section{HAL Id: hal-02398141 \\ https://hal.science/hal-02398141}

Submitted on 6 Dec 2019

HAL is a multi-disciplinary open access archive for the deposit and dissemination of scientific research documents, whether they are published or not. The documents may come from teaching and research institutions in France or abroad, or from public or private research centers.
L'archive ouverte pluridisciplinaire HAL, est destinée au dépôt et à la diffusion de documents scientifiques de niveau recherche, publiés ou non, émanant des établissements d'enseignement et de recherche français ou étrangers, des laboratoires publics ou privés. 


\title{
SUBJECTIVE POSTURE IN TRIDIMENSIONAL SPACE
}

\author{
I. Israël ${ }^{1}$, I. Giannopulu² \\ ${ }^{1} \mathrm{LDC}, \mathrm{EPHE}$ \\ 41, rue Gay-Lussac \\ 75005 Paris, France \\ email : isabelle.israel@,neuf.fr \\ ${ }^{2}$ EPP-Catholic University of Paris \\ 23, rue de Montparnasse \\ 75006 Paris, France \\ email: igiannopulu@psycho-prat.fr \\ Running head: body representation \\ Correspondence to: I. Israël
}

\begin{abstract}
The internal representation of the body is intimately related to postural orientation. This assists us to correctly identify our position relative to the earth-vertical. The postural orientation about the pitch-Y axis is by default forward tilted while there is no such default about the roll-X axis. We hypothetized that the internal representation of body position would be different between the $\mathrm{Y}$ and $\mathrm{X}$ axes. We designed a study to assess the accuracy of self-driven whole-body orienting to the horizontal and the vertical about the X (roll) and Y (pitch) axes, with healthy seated subjects in complete darkness. Consistent with our hypothesis, the results showed that when trying to reach the horizontal with the $\mathrm{X}$-axis, subjects remained on the same tilted direction as the initial posture. On the return way to the vertical, the subjects did not cross this vertical "boundary". Whereas when reaching the horizontal with the Y-axis, there was an undershoot on the supine direction, and an overshoot on the prone direction: this discrepancy could be due to somatosensory cues to subjects in seated posture. The relevant mechanisms related to the internal representation of the body and graviceptive systems underlying the construction of an head-foot line are discussed.
\end{abstract}

Keywords: internal representation, vestibular system, somatosensory system, multisensory interactions 


\section{Introduction}

To perceive our own orientation in space, the brain needs to compute and continuously update spatial information which is the base of the internal representation of the body in space. This internal representation is a dynamic process, enabling conscious and unconscious perception of body. Dynamic in nature, the vestibular system is crucial [21, 3, 4]. Furthermore, it has been established the existence of two interdependent somatosensory graviceptive systems in humans, aside from the otoliths of the vestibular system : the vascular graviceptive system and the kidneys (truncal graviceptive system) [38, 40].

The internal representation of body posture and orientation in space has already been amply studied in humans, showing the importance of this topic. For example, experiments have been carried out through apparent postural vertical or apparent upright $[7,12]$ on the Roll-X-axis. Postural vertical was most often studied with the roll or $\mathrm{X}$-axis, although some experiments were also reported about postural vertical with the pitch or Y-axis [1, 8]. Furthermore, postural horizontal has less often been examined with the $\mathrm{X}$-axis $[38,12]$ and with the $\mathrm{Y}$-axis $[15,30]$. But a direct comparison of postural horizontal on each $\mathrm{X}$ and $\mathrm{Y}$ axes still remains to be examined, to our knowledge.

Based on these previous postural vertical and horizontal perception studies, we designed a new study whose aim was to compare and distinguish the internal representations of the healthy human body, in a task of self-controlled whole-body orienting about roll (X-axis) and pitch (Y-axis) rotation axes.

Variations in the judgment of the postural vertical can be due to the direction of the initial tilt, the speed of return to upright, the magnitude of the initial tilt, the delay of time in the initial tilt, and the availability of somatosensory cues from the chair [21].

With the exception of one study [31] where high rotational velocity $\left(180^{\circ} / \mathrm{s}\right)$ was used to estimate body orientation in the dark, all studies about postural horizontal/vertical have been performed at very low rotational velocity $\left(0.5^{\circ} / \mathrm{s}, 1^{\circ} / \mathrm{s}, 1.5^{\circ} / \mathrm{s}\right.$, or $\left.5^{\circ} / \mathrm{s}\right)$. In this study, the authors obtained slightly more accurate data than the other known reports on body tilt estimates. In our study, we used $45^{\circ} / \mathrm{s}$ peak velocity so that the motion and somatosensory graviception information would help the subjects to reach the requested orientations (Horizontal and Vertical). 
Seated on a rotating chair, 10 subjects were required to position themselves horizontally $\left(=90^{\circ}\right)$ from different initial tilt of body, in complete darkness, and thereafter vertically $\left(=0^{\circ}\right)$. We evaluated the accuracy of body orientation and compared it between both directions for $\mathrm{X}$ and $\mathrm{Y}$-axes. Our hypothesis is that the internal representation of body orientation would be different between these both axes.

\section{Methods}

\subsection{Experimental apparatus}

The experimental set-up is an opaque fibreglass sphere of $1.95 \mathrm{~m}$ diameter (Fig. 1), mounted within three rings whose two outer rings are motor-driven [28, 2]. The outermost ring rotates about the earth-horizontal axis. The axis of the next ring is fixed to the outermost ring and is earth-vertical when the apparatus is in the initial position. The third ring fixed to the sphere can be manually rotated and secured to the second ring. The motors are controlled by a PC, and input-output signals are conveyed via slip-rings. A chair is fixed at the bottom inside the sphere.

In the present experiments, subjects were completely immobilized in a depressurized system which attenuates gravity-based on somatosensory cues, and secured onto the chair with three belts; the head was maintained inside a fixed helmet. The chair position was adjusted so that the head of the subject was at the centre of the two (X \& Y) rotation axes of the sphere. Two push-buttons were fixed on the right side of the chair, with which the subject could control sphere position, each button controlling one direction of the current rotation axis. The rotations imposed by the experimenter had $45^{\circ} / \mathrm{s}$ maximal velocity with $30^{\circ} / \mathrm{s}^{2}$ acceleration. The rotations controlled by the subject with the push-buttons had also $45^{\circ} / \mathrm{s}$ maximal velocity but $90^{\circ} / \mathrm{s}^{2}$ acceleration, so that the "chair" had a better pickup when driven by the subject. Sphere (i.e. head) position and velocity, and button on/off impulses were recorded during the experiment at $40 \mathrm{~Hz}$ sampling rate and stored on the PC for off-line analysis (Fig. 2).

Two particularities due to the set-up should be outlined: a) the subject had the hips and knees both flexed by about $90^{\circ}$ (seated), and b) the subject's head was at the centre of rotation, for both $\mathrm{X}$ and $\mathrm{Y}$ rotation axes. 


\subsection{Experimental procedure}

The subject was first positioned by the experimenter at an initial body tilt (IT) of $0^{\circ}$ (i.e., Vertical), $60^{\circ}$ or $120^{\circ}$, and stayed in that situation during 3-5 s. The subject was then required to orient his/her body (i.e. the trunk) at $90^{\circ}$ (i.e., Horizontal) with the pushbuttons, thereby indicating his/her own Subjective Postural Horizontal (SuPH). Five seconds after subject's orientation movement, s/he had to rotate back to upright, still in darkness, now indicating Subjective Postural Vertical (SuPV). After SuPV had been reached, the chair was slowly $\left(1^{\circ} / \mathrm{s}\right)$ rotated toward the true earth-vertical (i.e., $0^{\circ}$ ) by the experimenter, when needed.

The experiment was organized into blocks, one block containing pseudo-randomly 6 trials about one axis, one trial for each IT and each side: Right or Left for X-axis trials, and Prone or Supine for Y-axis rotations. Sides were systematically alternated, and all blocks were repeated four times. The set-up was in complete darkness during the whole experiment ( 3 ITs $\mathrm{x} 2$ sides $\mathrm{x} 4$ repetitions $\mathrm{x} 2$ axes $=48$ trials).

Ten subjects, with an age range of 25 to 40, without history of vestibular disease and with normal neuro-otological examinations, gave their informed consent to take part in the experiment, that had been accepted by the local ethical committee. Experiment was conformed to the Helsinki convention.

\subsection{Data analysis}

Final head (and trunk) orientation at Subjective Postural Horizontal (SuPH) and Subjective Postural Vertical (SuPV), and self-driven rotation amplitude and direction to reach those were taken into account. Analyses were computed with the averaged values of the four repetitions recorded at each of the three different initial body tilts (ITs) on both sides for each subject, thus on 60 data points ( 3 ITs $* 2$ sides $* 10$ subjects) for each axis and for both SuPH and SuPV; a two-factors (side* IT) repeated measures ANOVA was systematically applied. The significant effects reported have all $\mathrm{p}<0.05$. 


\section{Results}

3.1. $\mathrm{X}$-axis (roll)

\subsubsection{Subjective Postural Horizontal (SuPH)}

While the expected (ideal) $\mathrm{SuPH}$ was $90^{\circ}$, that measured on the $\mathrm{X}$-axis was $91.2 \pm$ $9.7^{\circ}$ (mean $\pm \mathrm{SD}, \mathrm{n}=60$ ), with no difference between the right and left sides. There was a significant effect of IT $(\mathrm{F}[2,18]=9.4, \mathrm{P}<0.002)$ on SuPH, that was $87.4 \pm 9^{\circ}$ when IT was $60^{\circ}, 93.3 \pm 7.8^{\circ}$ when IT was $120^{\circ}$, and $92.8 \pm 10.8^{\circ}$ when IT was $0^{\circ}$. It can be seen that $\mathrm{SuPH}$ with IT of $0^{\circ}$ had a slightly greater variability than for each other IT. Furthermore for both $60^{\circ}$ and $120^{\circ}$ ITs, i.e., for both non-zero ITs, the SuPH was slightly "attracted" toward the initial orientation (Fig. 3).

Different initial body tilts were used in order to detect a potential effect of this body orientation. This effect was seen to exist, since IT indeed influenced SuPH; but because of these ITs different angle magnitudes had to be travelled to reach the same expected horizontal orientation, and furthermore for SuPH at IT of $120^{\circ}$ there was a change of direction between the imposed rotation to IT and the next self-driven one from IT to SuPH. The analysis of the self-driven angles amplitudes showed that while those to SuPH with IT of $0^{\circ}$ were in average greater than the $90^{\circ}$ expected, the traveled angles when IT was $60^{\circ}\left(27.4 \pm 9.0^{\circ}\right)$ and when IT was $120^{\circ}\left(26.7 \pm 7.8^{\circ}\right)$ were not different and both slightly smaller than the $30^{\circ}$ expected. Therefore, both SuPH when IT was not $0^{\circ}$ were undershot and there was no specific effect of the change of rotation direction when IT was $120^{\circ}$, with $\mathrm{X}$-axis rotations.

\subsubsection{Subjective Postural Vertical (SuPV)}

Overall SuPV was $0.6 \pm 4.2^{\circ}$ left tilted, hence very close to the ideal $0^{\circ}$. Mean SuPV when coming (leftward) from the right was $3.0 \pm 1.9^{\circ}$ right tilted and was $4.3 \pm 2.1^{\circ}$ left tilted when coming (rightward) from the left (Fig. 3); return to the vertical was in both directions undershot but the difference between Right and Left SuPV was not significant 
$(\mathrm{p}=0.053) . \mathrm{SuPV}$ when IT was $0^{\circ}$ was $2.6 \pm 2.1^{\circ}$ from (and remaining on) the Right side and $3.6 \pm 2.1^{\circ}$ from (and still on) the Left side.

This analysis confirmed that SuPV rotations mostly undershot the vertical, i.e., the subjects seldom crossed this virtual vertical boundary but stayed on the SuPH side they came from, while with SuPH from IT of $0^{\circ}$ (that required the same angle magnitude as SuPV), subjects could cross the horizontal boundary. Thus the subjects did not really try to replicate the outward $90^{\circ}$ rotation but rotated until they found/felt the vertical, with the $\mathrm{X}$-axis.

\section{2. $\mathrm{Y}$-axis (pitch)}

\subsubsection{Subjective Postural Horizontal (SuPH)}

With the Y-axis, the mean measured SuPH was $-77.3 \pm 10^{\circ}$ on the supine side (negative angle), and $101.1 \pm 12.4^{\circ}$ on the prone side (positive angle). Thus there was an absolute difference of about $11^{\circ}$ with the $90^{\circ}$ ideal horizontal on both sides (Fig. 4). Furthermore the difference in $\mathrm{SuPH}$ between the two sides emerged quite clearly $(\mathrm{F}[1,9]$ $=38.1, \mathrm{P}<0.0002)$, with no effect of IT and no Side $*$ IT interaction.

When ANOVA was performed over the rotations amplitudes rather than on the reached angles, there was again a significant effect of side $(\mathrm{F}[1,9]=19.8, \mathrm{P}<0.002)$ and also of IT $(\mathrm{F}[2,18]=103.9, \mathrm{P}<0.0001)$, as well as a side $*$ IT interaction $(\mathrm{F}[2,18]=38.3$, $\mathrm{P}<0.0001)$. The effect of side confirmed that the rotation amplitudes with supine angles were smaller than those with prone angles. As for the side * IT interaction, all six mean amplitudes (2 Sides * 3 ITs) were significantly different from each other, except that of $60^{\circ} \mathrm{S}$ (Supine) compared to $120^{\circ} \mathrm{P}$ (Prone) and vice-versa $\left(120^{\circ} \mathrm{S}\right.$ and $60^{\circ} \mathrm{P}$ ): each couple of SuPH angles had actually in common not only the expected self-driven rotation amplitude, but also its direction. This revealed indeed a strong effect of rotation direction (toward or away from the prone or supine horizontal), with $-16.5 \pm 10.4^{\circ}$ amplitude toward supine and away from prone $\left(60^{\circ} \mathrm{S}\right.$ and $\left.120^{\circ} \mathrm{P}\right)$ and $40.6 \pm 11.7^{\circ}$ toward prone and away from supine $\left(60^{\circ} \mathrm{P}\right.$ and $\left.120^{\circ} \mathrm{S}\right)$. From IT $=0^{\circ}$, the travelled angle to SuPH Prone was $101.8 \pm 12.1^{\circ}$ and to SuPH Supine was $-78.4 \pm 10.9^{\circ}$ (Fig. 5). 
In summary, supine pitch rotations toward SuPH were smaller than expected and prone rotations larger, for all ITs.

\subsubsection{Subjective Postural Vertical (SuPV)}

With the Y-axis, there was no significant effect of side on the SuPV. However, SuPV when coming from supine $\left(-1.8 \pm 4.2^{\circ}\right)$ was slightly closer to the true vertical than when coming from prone $\left(4.6 \pm 3.1^{\circ}\right)$, so that the overall SuPV $\left(1.4 \pm 4.9^{\circ}\right)$ was slightly forward tilted (it was $0.6 \pm 4.2^{\circ}$ left tilted on the X-axis; Fig. 4). When IT was $0^{\circ}$, SuPV was $-0.1 \pm$ $5.3^{\circ}$ when coming from supine, and $4.4 \pm 3.5^{\circ}$ from prone.

For the rotations amplitudes, however, there was a significant effect of side $(\mathrm{F}[1,9]=$ 707.09, $\mathrm{P}<0.0001$ ), with $75.5 \pm 11.2^{\circ}$ from supine and $96.5 \pm 14.3^{\circ}$ from prone, which corresponded (it was the opposite) to the large effect of side observed on SuPH.

\section{Discussion}

In this experiment we assessed and compared the accuracy of body orientation with respect to the earth-horizontal and vertical, on the two X (roll) and Y (pitch) axes. Consistent with our hypothesis, the results show that the internal representation of body orientation is different according to these two rotation axes. Our results also show that there was a systematic and symmetrical difference between the prone and supine sides on the Y-axis. More precisely, the subjects turned too much on the prone side (ca. $11^{\circ}$ ), and not enough on the supine side (also about $11^{\circ}$ ), when trying to align along the earthhorizontal on this pitch-axis. In the contrary, there was no side effect on the $\mathrm{X}$-axis. This seems to confirm a basic difference between both axes, which relies most probably on the internal representation of body orientation.

\subsection{Comparison with existing results}


In a study subjects were lying on a rotating bed on the pitch-axis, in total darkness [15]. Starting at an erect position, subjects pitched themselves (at $5 \%$ s) to the prone position then until supine. Small body tilts in the sagittal plane were underestimated. In contrast, large forward body tilts tended to be overestimated ( $84^{\circ}$ prone); however, large backward body tilts were estimated quite accurately ( $89^{\circ}$ supine). This result, opposite to what we found, could be due to the fact that subjects were lying on a bed, in the above experiment, while they were seated in our case. But it could also be due to the highest velocity that we used, and also to the fact that the head was the rotation center in our study. However, researchers obtained results concordant with ours: normal subjects signaled that they were entering verticality at a tilt of $1 \pm 1.7^{\circ}$ in roll and $1.5 \pm 2.2^{\circ}$ in pitch [1]. Because the subjects signaled being tilted forward at a higher angle $\left(7.1 \pm 2.2^{\circ}\right)$ than being tilted backward $\left(-6 \pm 2.2^{\circ}\right)$, the width of the sector during backward motion in pitch was significantly smaller than the sector during forward motion. Two recent studies $[29,30]$ also got result very similar to ours, as actively pitched (at $1 \%$ s) seated subjects clearly undershot the horizontal with supine SuPH (ca. $-60^{\circ}$ ) and overshot it $\left(\mathrm{ca} .+100^{\circ}\right)$ for prone SuPH. The authors suggested a change of reference hypothesis to account for this discrepancy, which does probably not apply in our case because the subject's head was at rotation centre in our experiment.

In a more recent study [8] subjects were seated in a padded chair, and were passively tilted of $15^{\circ}$ to either side around the vertical at $1.5^{\circ} / \mathrm{s}$, in roll and pitch. Subjects indicated when they began to feel upright, and again when they began to feel tilted. The width of the sector of verticality was $5.9^{\circ}$ for both pitch and roll.

\subsection{Static/dynamic parameters and symmetry}

With the X-axis, SuPH seemed "attracted" toward the initial body tilt: subjects remained less tilted than $90^{\circ}$ when the IT was smaller than $90^{\circ}$, and stayed more tilted than $90^{\circ}$ when IT was larger than $90^{\circ}$, while this was not the case with the Y-axis. This suggests a memory of previous static orientation, with the $\mathrm{X}$-axis, also observed with subjective visual vertical [21].

The fact that this effect was not observed in the Y-axis in our experiment suggests some basic perceptual difference between the two rotation axes. There was no static IT- 
attraction with the Y-axis in our experiment. An influence of initial bed pitch had been found [41], but attributed to adaptation of somatosensory receptors, while our subjects did not stay long at each body orientation. We rather observed a dynamic effect of rotation direction. Pitch rotations toward supine SuPH were smaller than expected and those toward prone larger, for all ITs.

As the orientation error magnitude for $\mathrm{SuPH}$ was the same (about $11^{\circ}$ ) on both directions with the $\mathrm{Y}$-axis, responses were indeed symmetrical. A tilted "head to foot" plane along which trunk orientation on both sides was aligned was probably computed and certainly represented by our subjects.

Therefore, while orientation about the roll-X-axis is based on static positions or orientations, the pitch-Y-axis seems tuned to movement. The $\mathrm{Y}$-axis is the dynamic axis, about which we most often fall, jump, somersault. In vection experiment, the pitch-down sensation is stronger than the pitch-up one, while there was no such asymmetry in roll vection: these results could be compared with the present ones, both for the directional asymmetry and its dynamic aspect [27]. It has also been reported that the vection-onset latencies were longer in the horizontal axis than in the vertical one, but the vection-onset latencies did not vary between directions within each axis [17].

\subsection{Somatosensory systems and internal representation of the body}

With the Y-axis, SuPV was slightly forward tilted. Similar postures have been found $[28,29]$, and also reported in water [34] and in microgravity [13, 14], i.e. when proprioceptive or otolithic gravity sensors were deficient, respectively.

Authors also described a strong effect of reduced somatosensory cues on subjective postural horizontal and vertical [21]. Indeed, with studies during water immersion, it had been suggested that the utricles do not provide good static indication of orientation [11, 32]. It was also noted that $10^{\circ}$ up or down from horizontal seems to be a range within which the otoliths are relatively insensitive in signaling head orientation relative to the gravitational force vector, which could explain our $\pm 11^{\circ} \mathrm{SuPH}$ error on the Y-axis [33]. When subjects attempted to set themselves to the upright through $\mathrm{X}$-axis when seated on a chair, all reported using pressure cues [12, 23]. A dominance of proprioceptive input 
over vestibular input has been shown through differential rotation of the feet and/or the trunk about the vertical Z-axis [24]. The authors concluded that, perceptually, the vestibular information is linked to the foot support body representation through proprioception. They further suggested that body position perception is built bottom-up with the feet related to space coordinates (vestibularly derived), the trunk related to the feet and the head to the trunk. Perception would use vestibular input to control for stationnarity of external references, and if true, would rely on these instead of the vestibular derived space reference. It had been also suggested that sensory information from vestibular system and from somatosensory afferents in feet and ankles plays an important role in determining the availability of postural strategies [26]. Finally, studies have clearly demonstrated the role of touch and pressure cues on apparent orientation during barbecue rotation [33], and during roll rotation [43].

In the present experiment, subjects were firmly embedded in deflated pillows, so that somatosensory cues were reduced. The forward tilted posture we observed represents probably a kind of "default" reaction to keep balance in critical situations. It is probably due to the proprioceptive backward-tilted referential of verticality [5]. Furthermore, researchers [6] revealed the existence of a synthesis of vestibular and somaesthetic graviception for which the posterolateral thalamus plays a major role, corresponding to a primary property of internal models and yielding the neural bases of the Aubert effect. They concluded that humans construct and update internal models of verticality in which somatosensory information plays an important role. But we suggest that mental imagery was also at play because when reaching SuPV from prone, subjects were more forward tilted than from supine: they behaved as if they could "see the vertical boundary", from supine (negative pitch angle), and therefore they stopped rotating right on it.

Thus, subjective postural horizontal and vertical rely on mental imagery and on the internal computation of an head-foot line, both involving an internal representational system [42] or "body scheme" [22] i.e. an internal body representation providing a basis for conscious perception of the body posture and including also functions in the processing of multisensory inputs at the unconscious level including somatosensory cues. 
With the Y-axis, subjective horizontal was about $11^{\circ}$ too high or too low. Consider a subject with $80 \mathrm{~cm}$ ear-hip and $50 \mathrm{~cm}$ knee-feet length, and with $30 \mathrm{~cm}$ hip-knee. The angle between ear and feet would then be $\operatorname{arctang}(30 / 130)=13^{\circ}$, rather close from the $11^{\circ}$ found. This suggests that subjects adjusted the orientation not of their trunk, but of a "virtual line" joining head and feet. This "virtual line" materializes the internal representation of the body. It is based on vestibular, somatosensory and vascular graviceptive afferents. When reaching subjective vertical, whereas this virtual head-feet line assumption does not strictly hold anymore, subjects still seemed to be attracted toward it on the forward direction and front side. The trunk axis weight is probably increased due to its real weight, now parallel to the gravity vector.

Considering the above, it is reasonable to suggest that the internal representation or internal model of the body was also at play because when reaching SuPV from prone, subjects were more forward tilted than from supine. The subjects behaved as if they could "see the vertical boundary", from supine, and therefore they stopped rotating right on it. These results tell us that the rotation about the earth-horizontal axis (Y-axis) contributes to the internal representation of verticality. It is also possible to suggest that this rotation not only "reorients" the canal and otolith information relative to gravity but also transforms somatosensory graviception. Both receptors seem to be interdependent in order to lead to a robust judgement of vertical postural sense [3]. Our behavioural findings seem to be coherent with neurophysiological data showing that vestibular, somatosensory and graviceptive afferents and the Bayesian probability theory [16] established that the perception of self-motion direction relies on integration of multiple sensory cues. All these afferents are interconnected in cortical and sub-cortical levels [9] are transformed into representations that contribute to internal representation of the body [42]. 
Acknowledgements: This work was supported by the Alexander von HumboldtFoundation, Germany (I.I.). The authors are grateful to E. Koenig who gave to I.I the opportunity to realize this study, to K. Bechert, M. Fetter and H. Misslich for their assistance during the experiments, and to F. Maloumian (Paris) for the illustrations of this paper. 


\section{FIGURES CAPTIONS}

Fig.1: The 3D rotating chair of Tübingen University.

Fig.2: Recording of some sample trials. The thick line shows chair position, with chair velocity superimposed in thinner line. The steps line at the top shows button press.

Explanations: With the X-axis, when instructed to reach the horizontal on the Left direction from $0^{\circ}$ (upright) initial tilt (panel A), the subject pressed and released the button quickly and repeatedly so as to move slowly toward horizontal, as can be seen from the impulses-contingent velocity peaks and the staircase-like angular position of the chair. At the end, the subject pressed on the button controlling the other direction so as to adjust final orientation. On the "return" way to reach the vertical for the same trial, the subject pressed once to travel most of the rotation, and tried to adjust the position only at the end. The next trial (IT of $120^{\circ} \mathrm{R}$, panel B) also exhibits this segmentation of the rotation, but not as much as in panel A. Panel C shows a trial where a fairly straight strategy is used, with the Y-axis. Only some corrections or hesitations can be seen at the end of the return rotation of this negative pitch trial (IT of $60^{\circ} \mathrm{S}$ ), and no correction at all for the last positive pitch trial with IT of $0^{\circ} \mathrm{P}$ (panel D).

Fig.3: Mean subjective Horizontal and Vertical on the X-axis. Shaded shapes represent pooled right and left SuPH, from $60^{\circ}$ IT and $120^{\circ}$. White shapes show right and left SuPV. Difference between right and left in both SuPH and SuPV conditions was not significant.

Fig.4: Mean subjective Horizontal and Vertical on the Y-axis. Prone and supine SuPHs are shown with all ITs averaged (shaded shapes), and the same for SuPV (white shapes).

Fig.5: Travelled angles until SuPH on the Y-axis, showing the effect of rotation direction. 


\section{References}

[1] D. Anastasopoulos, K. Bhatia, A.R. Bisdorff, A. Bronstein, M.A. Gresty, and C.D. Marsden Perception of spatial orientation in spasmodic torticollis .1. The postural vertical, Mov Disord 12 (1997a), 561-569.

[2] D. Anastasopoulos, T. Haslwanter, A. Bronstein, M. Fetter and J. Dichgans, Dissociation between the perception of body verticality and the visual vertical in acute peripheral vestibular disorder in humans, Neurosi Lett 233 (1997b), 151-153.

[3] D.E. Angelaki, Eyes on target: what neurons must do for the vestibuloocular reflex during linear motion, J Neurophysiol 92 (2004), 20-35.

[4] D.E. Angelaki and K.E. Cullen, Vestibular system: the many facets of a multimodal sense, Annu Rev Neurosci 31 (2008), 125-150.

[5] G. Barbieri, A.S. Gissot, F. Fouque, J.M. Casillas, T. Pozzo and D. Perennou, Does proprioception contribute to the sense of verticality? Exp Brain Res 185 (2008), 545-552.

[6] J. Barra, A. Marquer, R. Joassin, C. Reymond, L. Metge, V. Chauvineau and D. Pérennou, Humans use internal models to construct and update a sense of verticality, Brain 133 (2010), 3552-3563.

[7] M. Bauermeister, Effect of body tilt on apparent verticality, apparent body position, and their relation, J Exp Psychol 67 (1964), 142-147.

[8] A.R. Bisdorff, C.J. Wolsley, D. Anastasopoulos, A. Bronstein and M.A. Gresty, The perception of body verticality (subjective postural vertical) in peripheral and central vestibular disorders, Brain 119 (1996), 1523-1534.

[9] T. Brandt and M. Dieterich, The Vestibular Cortex: Its Locations, Functions, and Disorders. A NY Aca Scienc 871 (1999), 1749-6632.

[10] L. Bringoux, V. Nougier, P.A. Barraud, L. Marin, and C. Raphel, Contribution of somesthetic information to the perception of body orientation in the pitch dimension. $Q$ J Exp Psychol [A] 56 (2003), 909-923.

[11] J.L. Brown, Orientation to the vertical during water immersion Aerospace Med 32 (1961), 209-217.

[12] B. Clark and A. Graybiel, Perception of the postural vertical in normals and subjects with labyrinthine defects, J Exp Psychol 65 (1963), 490-494.

[13] G. Clément, A. Berthoz and F. Lestienne, Adaptive changes in perception of body orientation and mental image rotation in microgravity, Aviat Space Environ Med 58 (1987), A159-A163.

[14] G. Clément and F. Lestienne, Adaptive modifications of postural attitude in conditions of weightlessness, Exp Brain Res 72 (1988), 381-389.

[15] M.M. Cohen and C.A. Larson, Human spatial orientation in the pitch dimension, Percept Psychophys 3 (1974), 508-512.

[16] C.R. Fetsch, A.H. Turner, G.C. DeAngelis and D.E. Angelaki Dynamic reweighting of visual and vestibular cues during self-motion perception. J Neurosci 29 (2009), 15601 15612.

[17] I. Giannopulu and J.C. Lepecq, Linear-vection chronometry along spinal and sagittal axes in erect man, Perception 27 (1998), 363-372.

[18] S. Glasauer and I. Israël, Otholitic thresholds influence the perception of passive linear displacement, Acta Otolaryngol (Stockh) 115 (1995), 41-44.

[19] A.M. Green and D.E. Angelaki, Internal models and neural computation in the vestibular system, Exp Brain Res 200 (2010), 197-222. 
[20] A.M. Green, A.G. Shaikh, and D.E. Angelaki, Sensory vestibular contributions to constructing internal models of self-motion, J Neural Eng 2 (2005), S164-S179.

[21] F.E. Guedry, Psychophysics of vestibular sensation, in: Handbook of Sensory Physiology, Vol. VI/2 H.H. Kornhuber, New York: Springer Verlag, 1974, pp. 3-154.

[22] V.S. Gurfinkel, Y.S. Levik, K.E. Popov, B.N. Smetanin and V.Y. Shlikov, Body scheme in the control of postural activity, in: Stance and motion: Facts and concepts, V.S. Gurfinkel, M.E. Ioffe, J. Massion and J.P. Roll, New York: Plenum, 1988, pp. 185-193.

[23] A. Higashiyama and K. Koga, Apparent body tilt and postural after effect, Percept Psychophys 60 (1998), 331-347.

[24] F. Hlavacka, T. Mergner, and M. Krizkova Control of the body vertical by vestibular and proprioceptive inputs. Brain Res Bull 40 (1996), 431-434.

[25] F. Hlavacka, T. Mergner and G. Schweigart, Interaction of vestibular and proprioceptive inputs for human self-motion perception, Neurosci Lett 138 (1992), 161 164.

[26] F.B. Horak, L.M. Nashner and H.C. Diener, Postural strategies associated with somatosensory and vestibular loss, Exp Brain Res 81 (1990) 167-177.

[27] J.K. Huang and L.R. Young, Visual field influence on manual roll and pitch stabilization, Aviat Space Environ Med 59 (1988), 611-619.

[28] I. Israël, D. Sievering and E. Koenig, Self-rotation estimate about the vertical axis, Acta Otolaryngol (Stockh) 115 (1995), 3-8.

[29] Y. Ito and M.A. Gresty, Shift of subjective reference and visual orientation during slw pitch tilt for the seated human subject, Brain Res Bull 40 (1996), 417-421.

[30] Y. Ito and M.A. Gresty, Subjective postural orientation and visual vertical during slow pitch tilt for the seated human subject, Aviat Space Environ Med 68 (1997), 3-12.

[31] K. Jaggi-Schwarz and B.J.M. Hess, Influence of dynamic tilts on the perception of earth-vertical, Exp Brain Res 149 (2003), 340-350.

[32] T. Jarchow, and F.W. Mast The effect of water immersion on postural and visual orientation. Aviat Space Environ Med 70 (1999), 879-886.

[33] J.R. Lackner and A. Graybiel, Some influences of touch and pressure cues on human spatial orientation, Aviat Space Environ Med 49, (1978), 798-804.

[34] J. Massion, J.C. Fabre, L. Mouchnino and A. Obadia, Body orientation and regulation of the center of gravity during movement under water, J Vestib Res 5 (1995), 211-221.

[35] F. Mast and T. Jarchow, Perceived body position and the visual horizontal, Brain Res Bull 40 (1996), 393-397.

[35] F. Mast, M. Kosslyn, and A. Berthoz, Visual mental imagery interferes with allocentric orientation judgements, NeuroReport 10 (1999), 3549-3553.

[36] D.M. Merfeld, L. Zupan, and R.J. Peterka, Humans use internal models to estimate gravity and linear acceleration, Nature 398 (1999), 615-618.

[37] H. Mittelstaedt, New diagnostic tests for the function of utricles, saccules and somatic graviceptors, Acta Otolaryngol (Stockh) 115 Suppl. 520 PT 1 (1995), 188-193.

[38]H. Mittelstaedt, Origin and processing of postural information, Neurosci Biobehav Rev 22 (1998), 473-478.

[39] M.L. Mittelstaedt and H. Mittelstaedt, The influence of otoliths and somatic graviceptors on angular velocity estimation. J Vestib Res 6 (1996), 355-366.

[40] H. Mittelstaedt, Somatic graviception, Biol Psychol 42 (1996), 53-74.

[41] K. Nemire and M.M. Cohen, Visual and somesthetic influences on postural orientation in the median plane, Percept Psychophys 53 (1993), 106-116. 
[42] J. Paillard, Cognitive versus sensorimotor encoding of spatial information, in: Cognitive processes and spatial orientation in animal and man, P. Ellen and C. ThinusBlanc eds, Dordrecht: Martinus Nijhoff Publishers BV, 1987, pp. 43-77.

[43] M. Trousselard, P.A. Barraud, V. Nougier, C. Raphel, and C. Cian, Contribution of tactile and interoceptive cues to the perception of the direction of gravity, Cogn Brain Res 20 (2004), 355-362. 


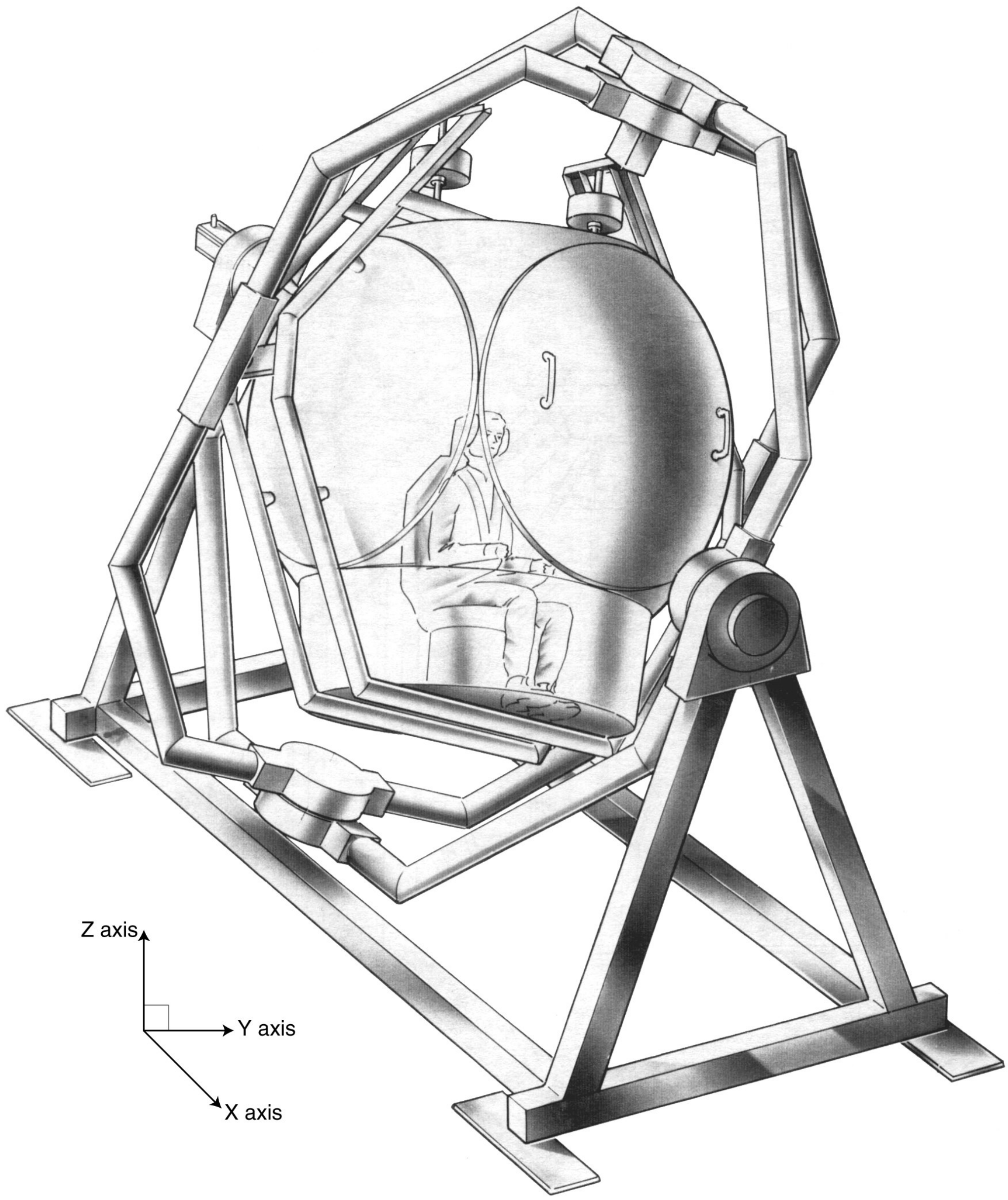



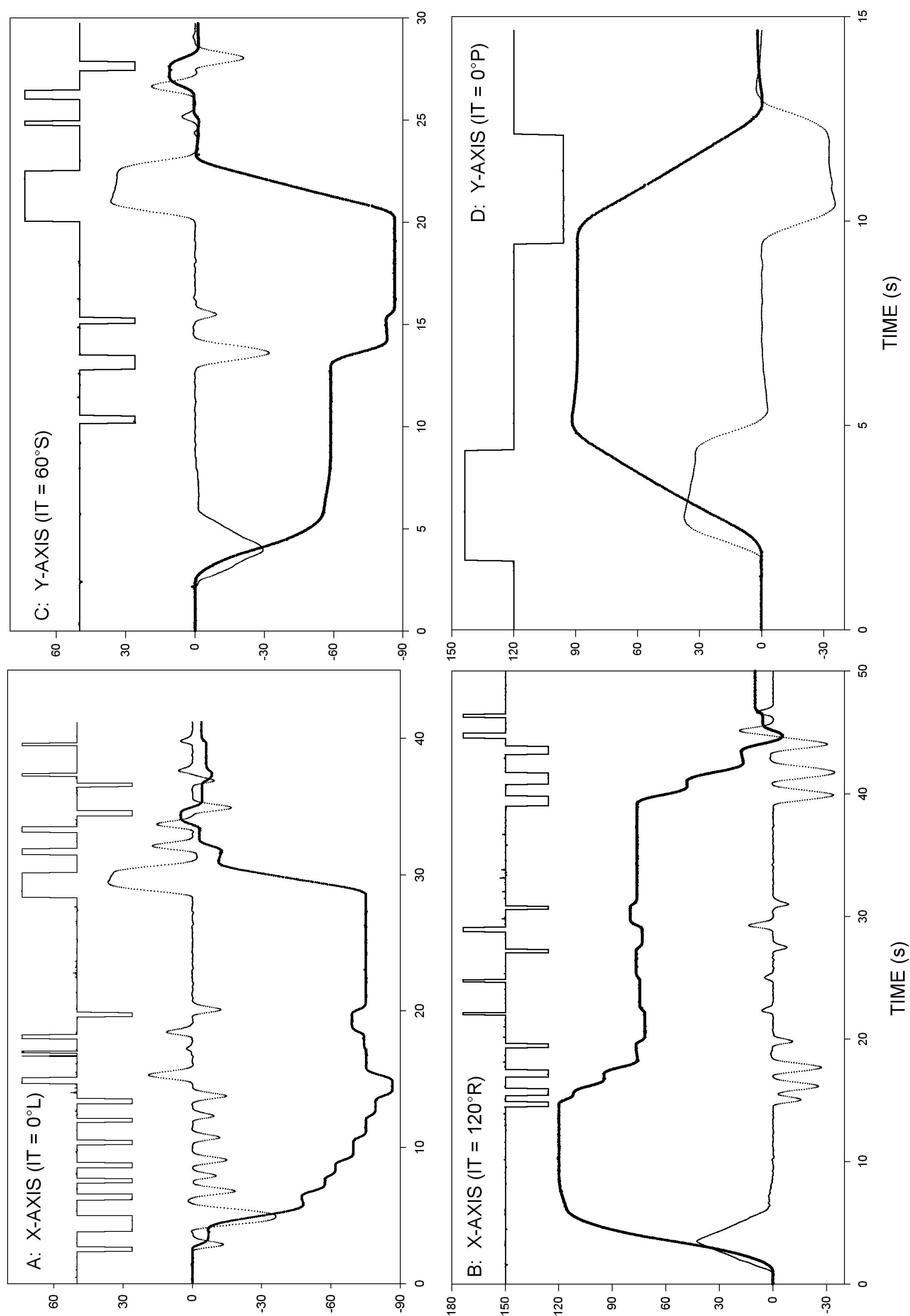

$(s / \%) \wedge \perp 1007 \exists \wedge$ pue $\left({ }_{0}\right)$ NOILISOd $y \forall 7 n O N \forall$

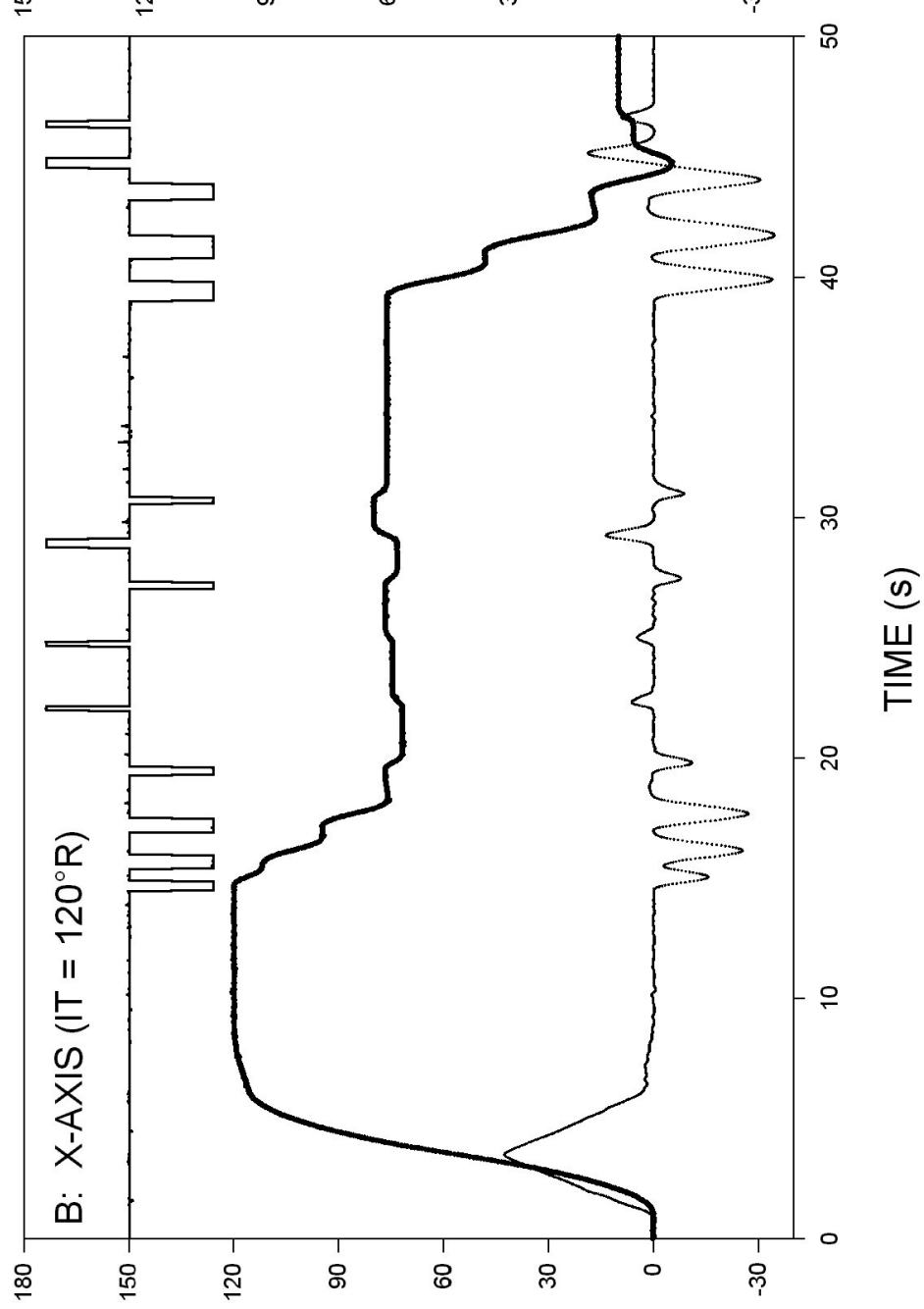

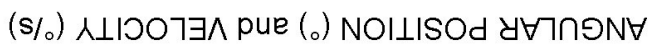




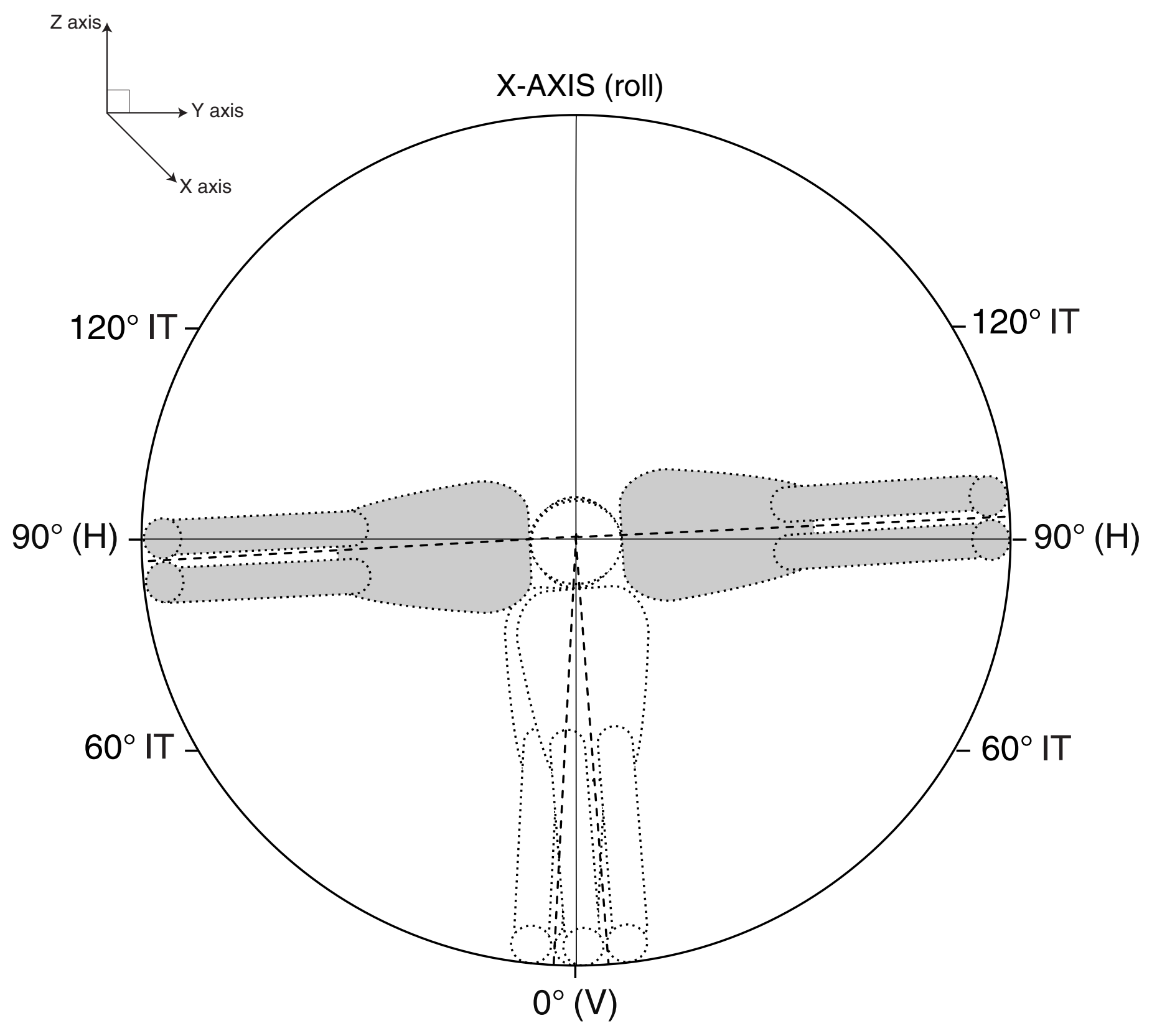




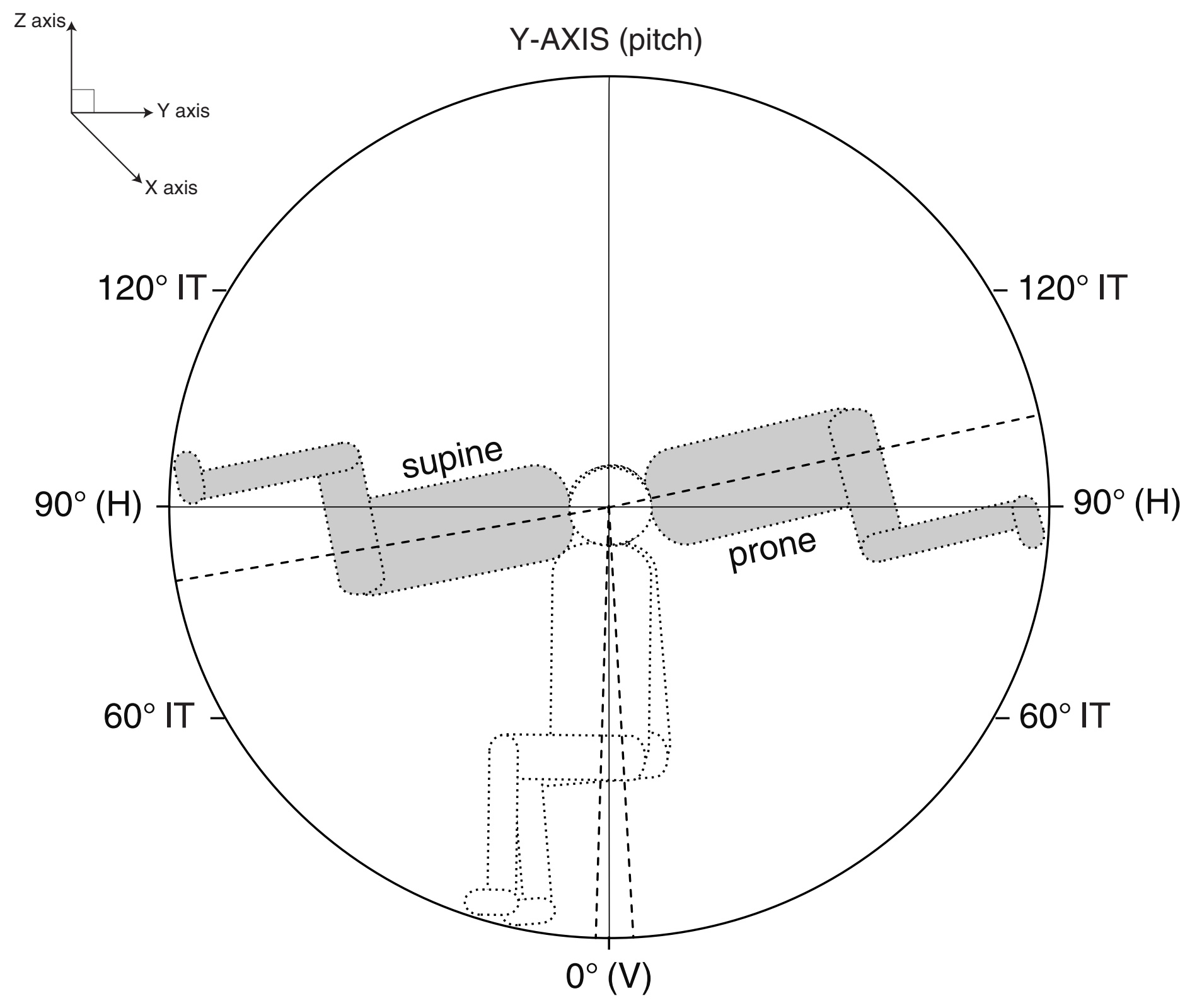




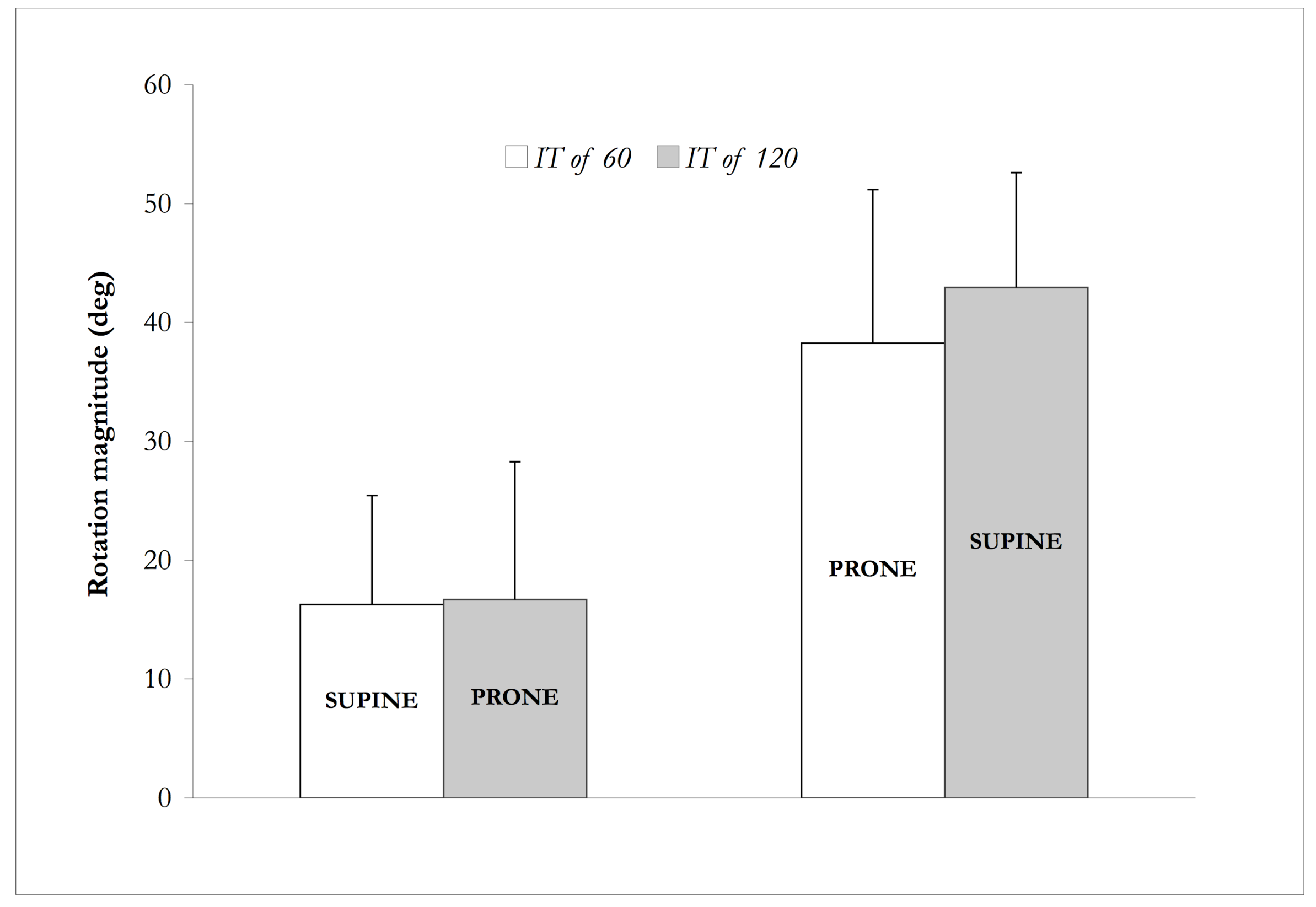

Fig. 5 Travelled angles until SPH (Subjective Postural Horizontal) 